\title{
Characterisation of the oxide film on the taper interface from retrieved large diameter metal on polymer modular total hip replacements
}

\author{
P. Zeng ${ }^{\mathrm{a}, *}$, W.M. Rainforth ${ }^{\mathrm{a}}$, R.B. Cook ${ }^{\mathrm{b}}$ \\ ${ }^{a}$ Department of Materials Science and Engineering, University of Sheffield, UK \\ ${ }^{\mathrm{b}}$ National Centre for Advanced Tribology at Southampton, University of Southampton, UK
}

\section{A R T I C L E I N F O}

\section{Article history:}

Received 30 June 2014

Received in revised form

2 November 2014

Accepted 7 December 2014

\section{Keywords:}

CoCrMo

Taper interfaces

TEM

EELS

\begin{abstract}
A B S T R A C T
Many metal joint failures have been associated with adverse local tissue reactions due to the response of the body to wear debris and corrosion products, released from the bearing surfaces or the taper interfaces. The oxide film on the CoCrMo plays an important role in the electrochemical behaviour, however, there is a lack of quantitative data on the structure and distribution of oxides following in vivo operation. In the present study, detailed analysis of the surface layer on the taper interfaces is provided. Two retrieved taper interfaces were analysed. Site-specific FIB/TEM cross-sections show evidence of the oxide film and the carbonaceous layer. High resolution TEM results show the oxide film has porous texture and EELS confirmed it is chromium oxide.
\end{abstract}

(c) 2014 Published by Elsevier Ltd.

\section{Introduction}

Metal debris and ions released from cobalt chromium molybdenum alloys have become a subject of interest due to the higher than expected failure rate of metal on metal (MoM) hip replacements which use these alloys [1,2]. The Medicines and Healthcare Products Regulatory Agency (UK) and the Food and Drug Administration (US) issued alerts for all MoM hip replacement in 2010 and 2011, respectively, with concerns about the adverse local tissue reactions (ALTR) to metal ions, resulting dramatic drop of the MoM market in recent years.

Metal ions and debris release are not only derived from the bearing surfaces, but can also arise from the taper interface between the head and stem components of modular total hip replacements. Release of material from this interface has been linked to ALTR from MoM [3-9] and Metal on Polymer (MoP) joints [3,10-13].

Langton et al. [14] reported data from 369 explanted metal-onmetal devices from various manufacturers and suggested that taper debris may be more biologically active than that derived from the bearing surfaces. Hart et al. [15] studied 53 large head metal-on-metal hip replacement and found that on an average the taper contributed $32.9 \%$ of the total wear volume. Furthermore, 'trunnionosis' is not only limited to MoM prostheses, but to all modular designs. Cooper et al. [16] reviewed the records of ten patients with metal-on-polyethylene (MoP) total hip prosthesis, and concluded that adverse local tissue reactions can occur in patients with a MoP bearing, in addition to corrosion at the

\footnotetext{
*Corresponding author. Tel.: +44 1142225519.

E-mail address: p.zeng@sheffield.ac.uk (P. Zeng).
}

modular femoral head-neck taper, and the presentation is similar to the adverse local tissue reactions seen in patients with a MoM bearings. Kurtz et al. [17] studied 50 retrieved ceramic head-stem pairs and 50 retrieved $\mathrm{CoCr}$ head-stem pairs and concluded that by using a ceramic femoral head, $\mathrm{CoCr}$ fretting and corrosion from the modular head-neck taper may be mitigated but not eliminated.

Corrosion and mechanical damage on the taper interfaces of retrieved total hip replacements (THRs) are not new topics, Gilbert et al. [18] studied 148 retrieved modular hip prostheses of both mixed (Ti6AL4V/CoCr) and similar $(\mathrm{CoCr} / \mathrm{CoCr}$ ) metal combinations and found the evidence of corrosion in the conical taper region between head and stem. Gilbert et al. [19,20] later described the mechanism of damage in the taper region as mechanically assisted crevice corrosion. It is well known that an oxide film is present on the surface of CoCrMo and plays an important role in the corrosion resistance of CoCrMo alloy [21-24]. Also, a tribo-layer due to tribochemical reactions has been widely observed in MoM prostheses by several authors [25-28]. However, there is a lack of quantitative data about the structure of these layers. In the present study, detailed analysis of near surface layers on the taper interfaces is provided using advance electron microscopies, such as focused ion beam (FIB), high resolution transmission electron microscopy (HRTEM) and electron energy loss spectroscopy (EELS).

\section{Material and methods}

\subsection{Retrieved implants}

The two retrieved femoral heads were a $40 \mathrm{~mm}$ (Case 1 ) and a $44 \mathrm{~mm}$ (Case 2) diameter zero offset Low Friction Ion Treatment 

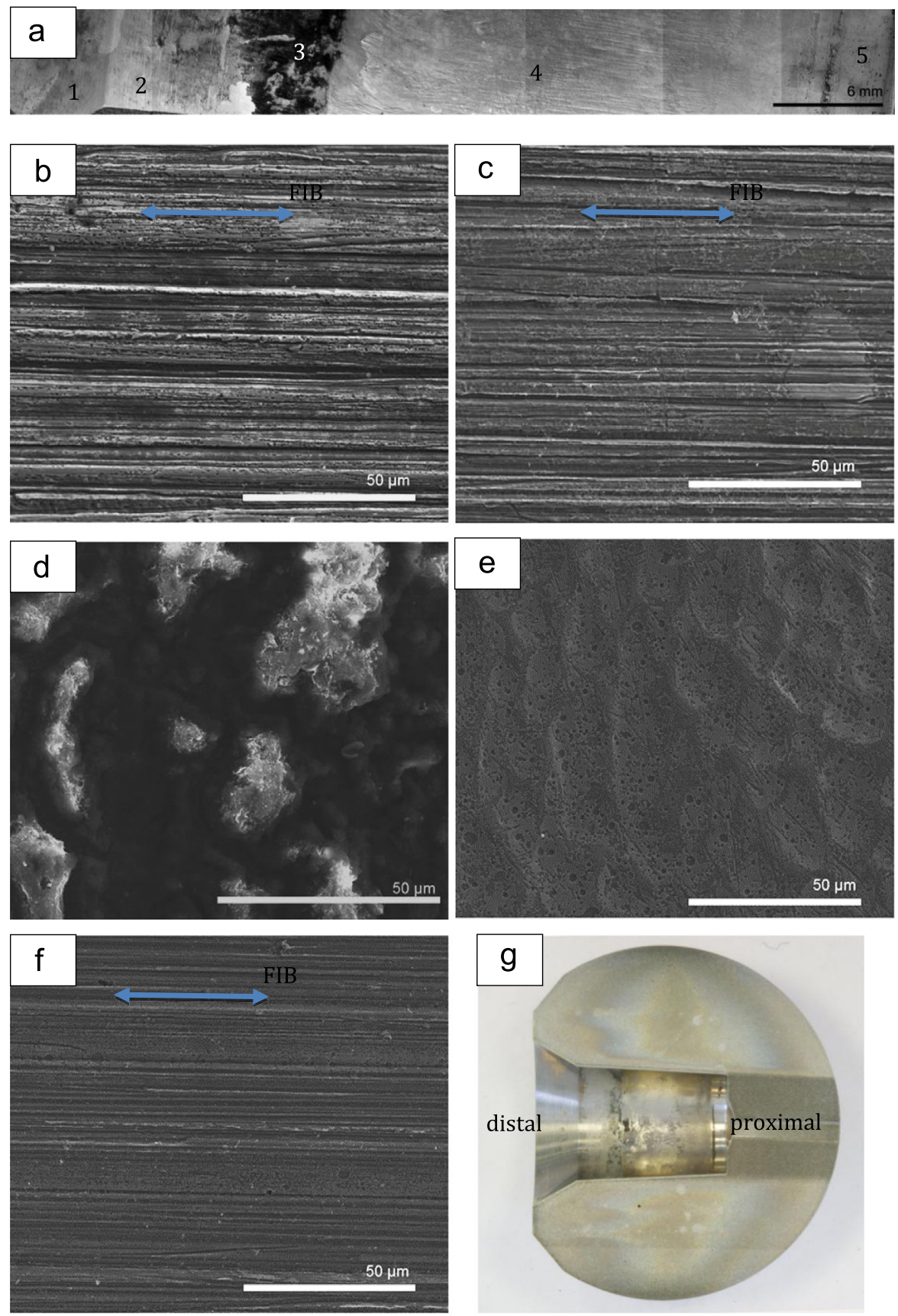

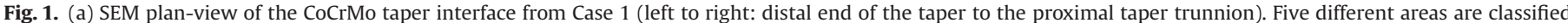

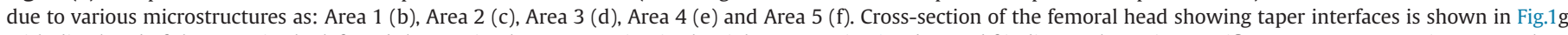

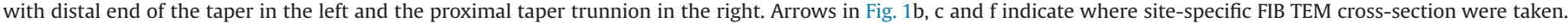
Note Fig. 1b-f are taken perpendicular to Fig. 1a.

(LFIT'M) CoCrMo anatomic heads which were both retrieved after 4 years in vivo. The bearing was a MoP articulation against a zero degree $X 3{ }^{\circledR}$ polyethylene liner in a Trident ${ }^{\mathbb{R}}$ HA (hydroxyapatite) coated acetabular shell made of Ti6Al4V ELI (Extra Low Interstitial). The stem was an Accolade ${ }^{\circledR}$ Femoral stem, made of a $\beta$-Titanium alloy (TMZF: titanium, molybdenum, zirconium and iron) [13].

In both Cases the stem and acetabular shell were left in vivo as they were considered well fixed, with no malposition or evidence of macroscopic damage during revision. Ethical approval was granted by the National Research Ethics Service Committee South Central-Southampton A. The samples were sterilised and stored separately in $10 \%$ buffered formalin.

\subsection{Surface and cross-section characterisation}

Surface morphologies of taper interfaces were initially characterised by scanning electron microscopy (SEM), using InspectF (FEI, the Netherlands) operating at $15 \mathrm{kV}$ and Nova (FEI, the Netherlands) operating at $5 \mathrm{kV}$. Case 1 was initially sectioned using an electrical discharge machine cut, followed by a more accurate cut using an IsoMet precision cutter (Buehler, UK) with a $\mathrm{SiC}$ saw and water cooling. Case 2 was sectioned only by IsoMet.

Site-specific TEM cross-sections of taper interfaces were prepared using a Quanta 200D FIB-SEM (FEI, The Netherlands). For Case 2, a gold coating was sputtered on the taper interfaces prior 

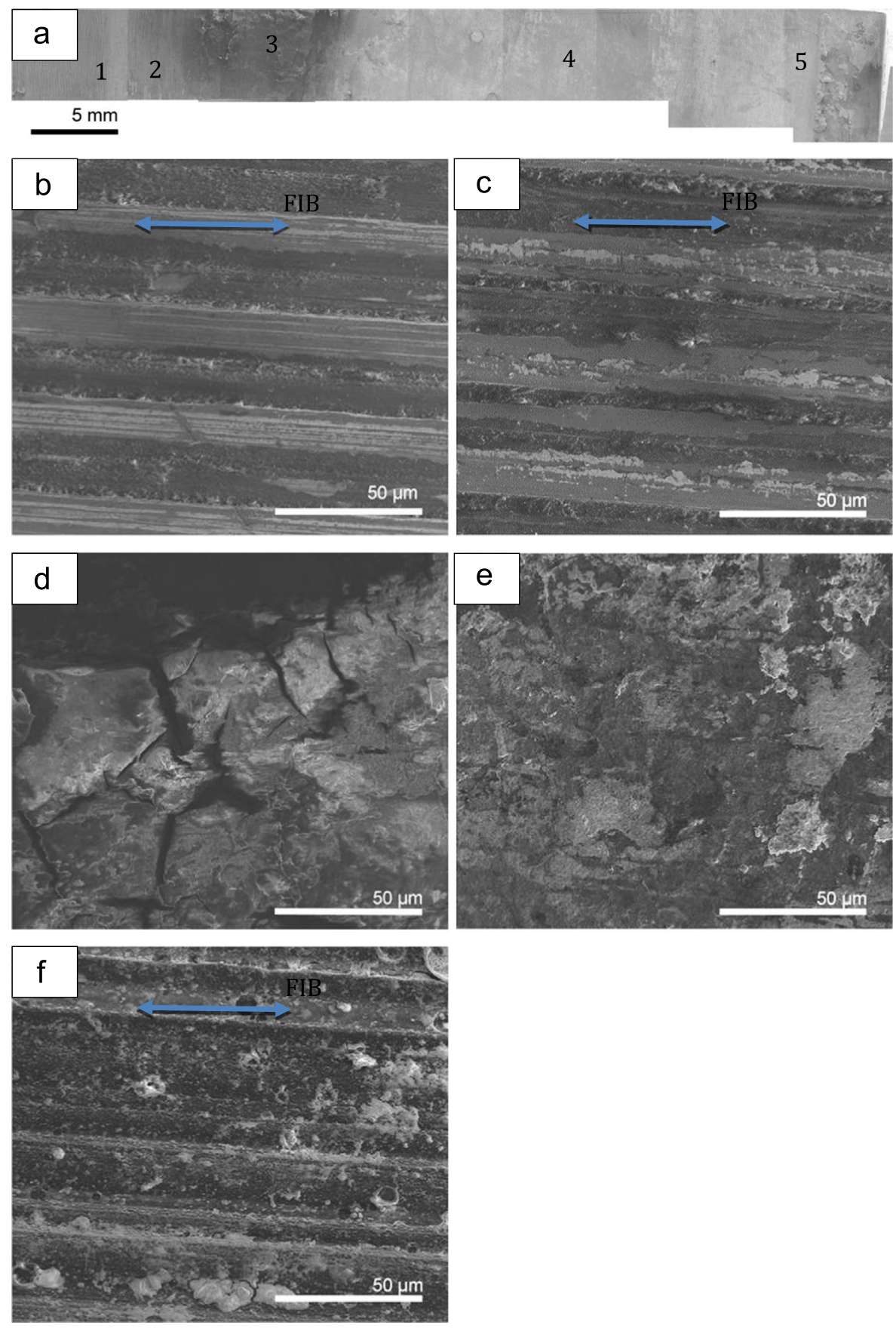

Fig. 2. (a) SEM plan-view of the CoCrMo taper interface from Case 2 (left to right: distal end of the taper to the proximal taper trunnion). Five different areas are classified due to various microstructures as: Area 1 (b), Area 2 (c), Area 3 (d), Area 4 (e) and Area 5 (f). Arrows in Fig. 2 b, c and f indicate where site-specific FIB TEM cross-section were taken. Note Fig. $2 \mathrm{~b}-\mathrm{f}$ are taken perpendicular to Fig. 2a.

to FIB milling to label the original surface. For both Case 1 and Case 2, a carbon layer was deposited on top of the area of interest before $\mathrm{Ga}^{+}$milling to protect the worn surface layer from exposure to the $\mathrm{Ga}^{+}$beam.

Various TEMs were used to examine site-specific TEM crosssections of taper interfaces, including Tecnai 20 (FEI, the Netherlands) operating at $200 \mathrm{kV}$, Jeol 3010 (JEOL, Japan) operating at $300 \mathrm{kV}$ and Jeol 2010F (JOEL, Japan) operating at $200 \mathrm{kV}$. Electron energy loss spectroscopy (EELS, Gatan GIF, USA) equipped on the Jeol 2010F was employed to analyse the cross-section samples. EELS measurements were made in conventional TEM diffraction mode (image coupling to the spectrometer). For each area, C K, N

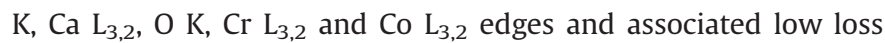
spectra were collected.

\section{Results:}

3.1. Plan view studies of the taper interfaces microstructure of Case 1 and Case 2

Fig. 1a is a SEM plan view of the CoCrMo taper surface of Case 1. From the distal (open) end of the surface to the proximal (central head) end (left to right) (as shown in Fig. 1g), five different areas 


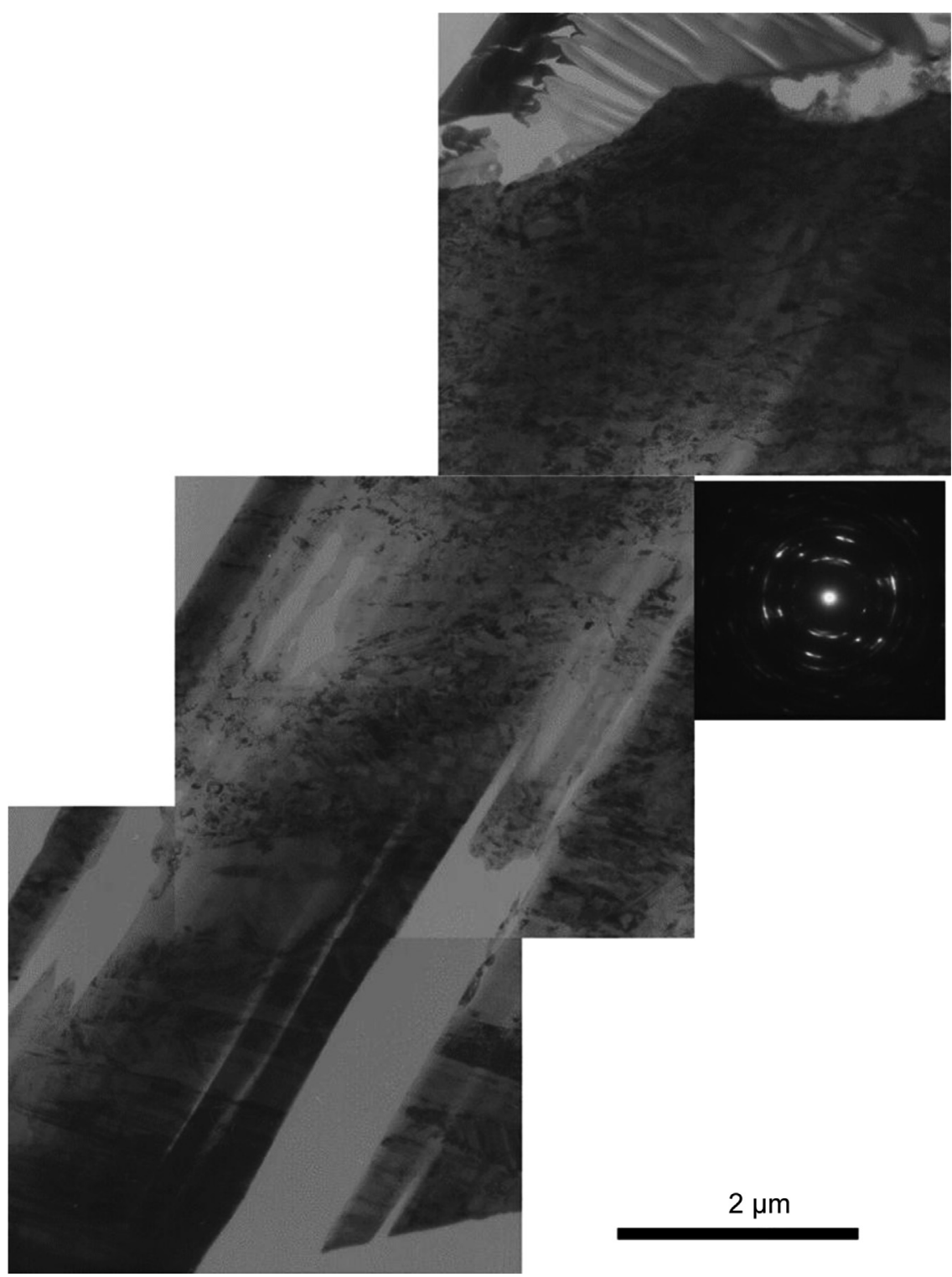

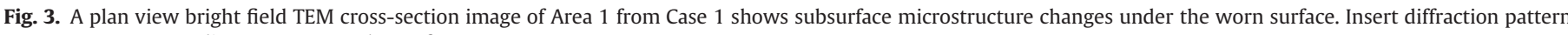
suggests a nanocrystaline structure at the surface.

can be identified, labelled Areas 1-5. Of these regions, Areas 2-4 are where the taper and trunnion were overlapping. Magnified SEM images of Areas 1-5 are shown in Fig. 1b-f, respectively. Area 1 (Fig. 1b) is the distal end of the taper and shows original machining marks. Area 2 (Fig. 1c), which was about $6 \mathrm{~mm}$ wide, shows similar machining marks to those observed in area 1 , however, there was evidence of some smoothing of the machining marks and microstructural features could be seen through etching of the grain and or phase boundaries. Area 3 (Fig. 1d), about $3 \mathrm{~mm}$ wide, exhibited denatured protein piling up on the surface, which obscured the underlying material. Area 4, which about $18 \mathrm{~mm}$ wide, was the largest area of the taper-trunnion overlap. This area exhibited evidence of extensive plastic deformation in the surface (Fig. 1a), but when viewed at higher magnification, Fig. 1e, there was evidence of pitting within the adzed texture of the surface, with all evidence of the original machining marks lost. Area 5, the proximal end of the taper trunnion, exhibited some evidence of the original machining marks, but otherwise a smooth surface with some evidence of fine scale corrosion (Fig. 1f).

Case 2 provided similar observations to Case 1 (Fig. 2). As with Case 1, five different regions could be classified as Areas 1-5, from the distal end of the taper to the proximal taper trunnion (left to right). Area 1 (Fig. 2b), the distal end of the taper, exhibited the original machining marks. Area 2 (Fig. 2c) was similar to Area 1, except the high points had been smoothed presumably through overlapping with the counterface. Area 3 (Fig. 2d) exhibited extensive pile up of denatured protein which obscured the metal subsurface. Area 4 (Fig. 2e) also showed extensive denatured protein, but also evidence of wear debris was observed. The wear debris (e.g. in the lower right of Fig. 2e) comprised particles that had a sheet like appearance, typically $10-30 \mu \mathrm{m}$ in diameter. Area 5 (Fig. 2f) exhibited the original machining grooves, but with wear debris randomly distributed across the surface. Interestingly, areas 1, 2, 3 and 5 of Case 1 show similar surface microstructures to Areas 1, 2, 3 and 5 of Case 2, except more surface debris is observed in Areas of Case 2. In contrast, Area 4 looked quite different in Cases 1 and 2.

\subsection{Cross-sectional studies of the taper interfaces}

A number of different wear/corrosion processes were observed from SEM images, but it is difficult to fully understand the 

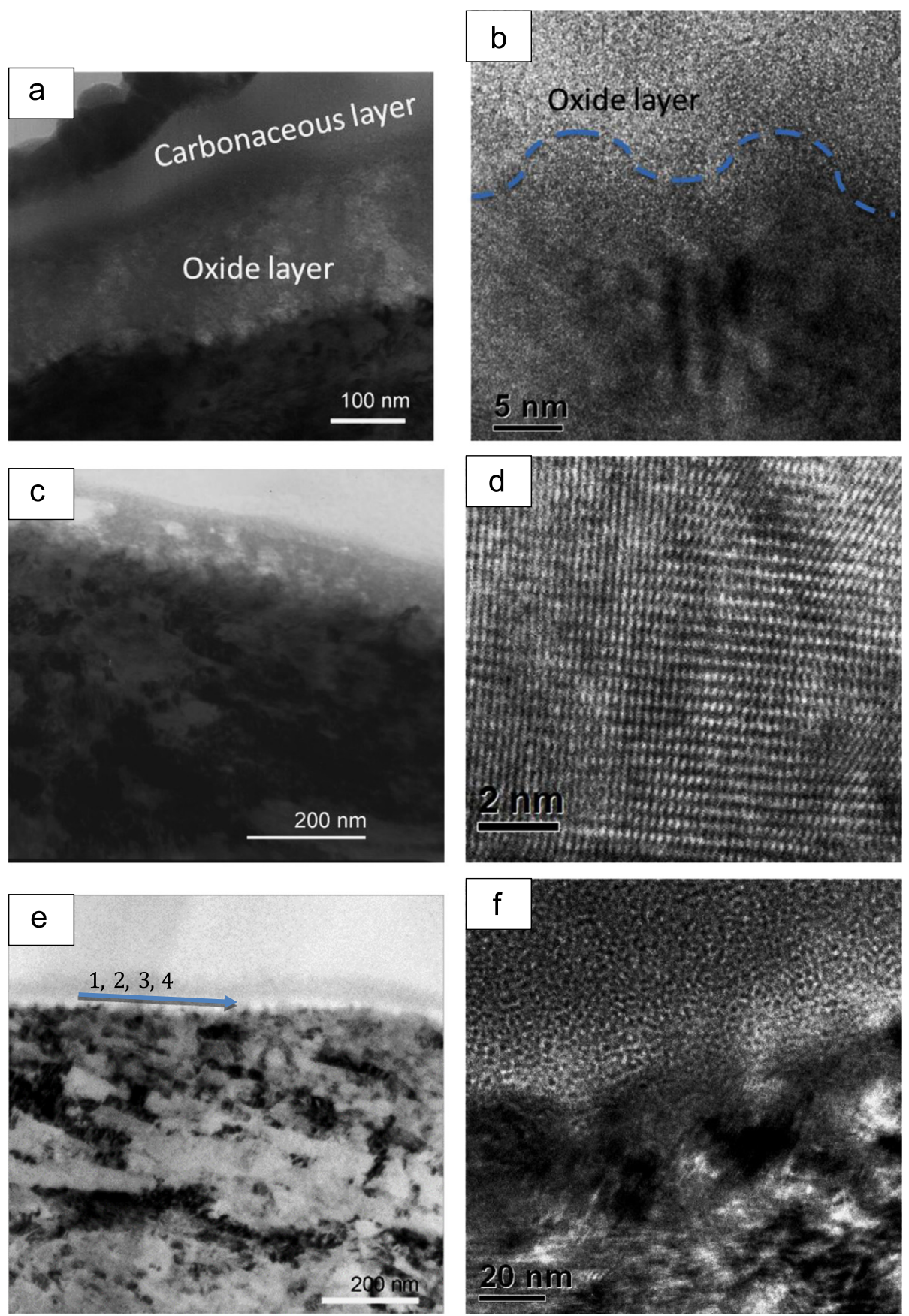

Fig. 4. Longitudinal bright field TEM images from cross-sections of Areas 1, 2 and 5 from Case 1. (a) Area 1 and (b) HRTEM of near surface zone in Area 1; (c) Area 2 and (d) HRTEM of nanocrystalline layer in Area 2; (e) Area 5 and (f) HRTEM of near surface zone in Area 5. Four regions 1-4 are marked in (e) indicating where EELS spectra (Fig.7) were taken.

mechanisms from plan view SEM images alone. Therefore, sitespecific TEM cross-sections were taken from Areas 1, 2 and 5 for both Case 1 and Case 2. Arrows in Fig. 1b, c and f and Fig. 2b, c and $\mathrm{f}$, indicate where FIB TEM cross-sections were taken.

\subsubsection{Case 1}

Fig. 3 is a bright field TEM montage taken from a FIB crosssection from Area 1 of Case 1. The sample was removed in the region indicated in Fig. 1b, i.e. parallel to the original machining marks. A nanocrystalline structure was observed under the surface, with the grain size of the order of $50 \mathrm{~nm}$. The inset diffraction pattern indicates that the nanocrystalline region exhibited a strong crystallographic texture. The nanocrystalline layer extended to about $5 \mu \mathrm{m}$ below the surface. Beneath the nanocrystalline layer the structure was a mixture of the face centred cubic (FCC) CoCrMo with plates of $\varepsilon$-martensite, which is the classical structure of CoCrMo alloys after low strain deformation.

A similar nanocrystalline layer was observed in the longitudinal cross-sections of Areas 2 and 5 from Case 1 (Fig. 4). However, the thickness of the nanocrystalline layer was smaller in those regions, being $\sim 1 \mu \mathrm{m}$ in Area 2 and $\sim 2 \mu \mathrm{m}$ in Area 5 . The sizes of the substructure in the nanocrystalline region also varied, being $\sim 100 \mathrm{~nm}$ in Area 2 and $\sim 30 \mathrm{~nm}$ in Area 5. 

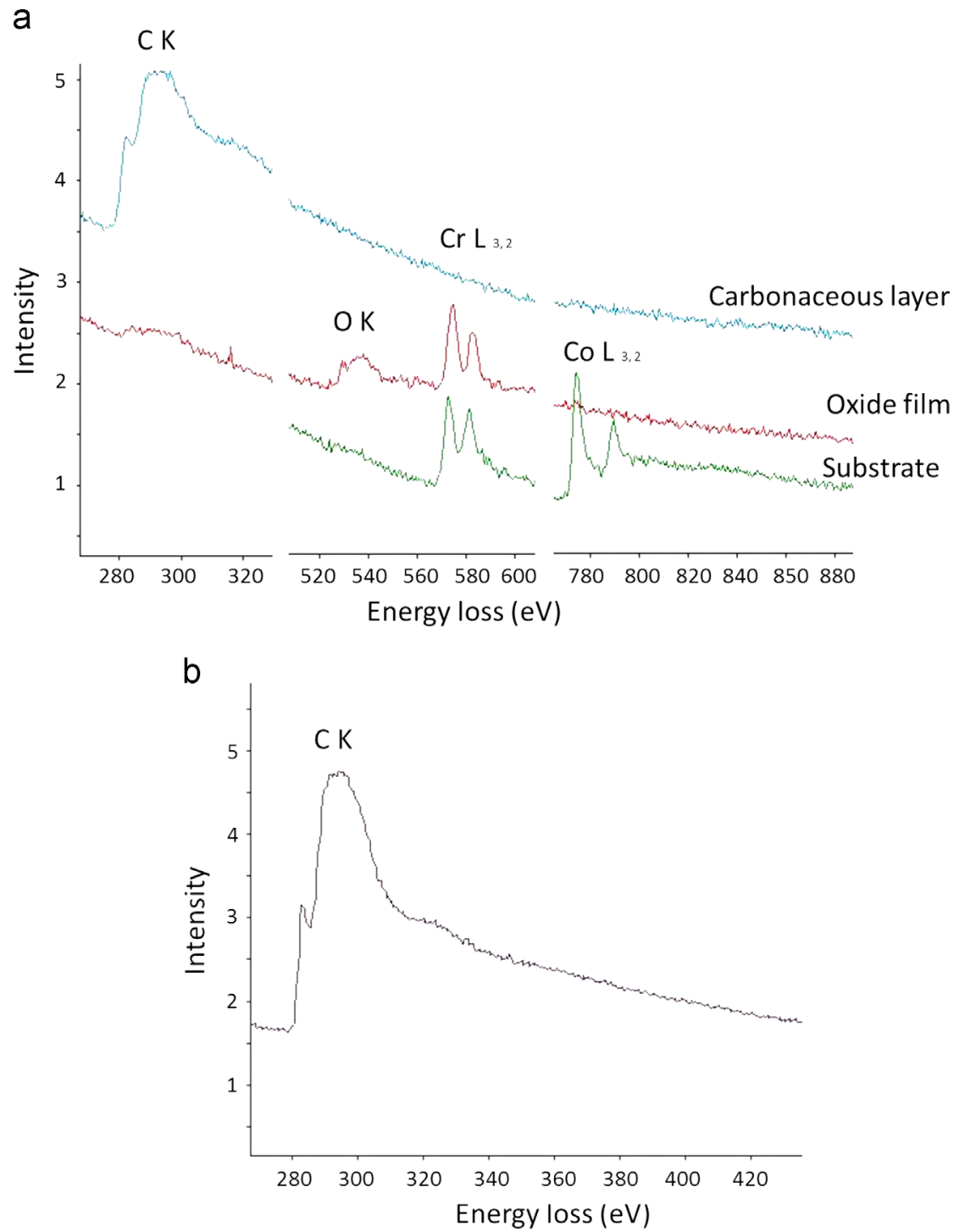

Fig. 5. (a) Normalised experimental EEL spectra from carbonaceous layer, oxide film and substrate of Area 1 of Case 1. (b) Standard amorphous carbon spectrum.

In some cases the nanocrystalline region extended up to the surface, but in most cases, the outer surface had a different structure. Fig. 4 details the surface region of Areas 1, 2 and 5 of Case 1. Fig. 4a is from Area 1 of Case 1. Two layers can be seen on the surface, namely an outer layer that appeared homogenous and exhibited uniform contrast, but with varying thickness, and beneath this a $\sim 200 \mathrm{~nm}$ thick porous layer. EELS results, which will be presented later, suggest that the outer layer was a carbonaceous layer, while the porous inner layer was an oxide film. Fig. $4 \mathrm{~b}$ is a HRTEM image of the interface between the oxide film and the nanocrystalline substrate, which shows that the oxide layer was amorphous.

Fig. $4 \mathrm{c}$ shows the near surface zone in Area 2 of Case 1. Again, an outer carbonaceous layer is present, followed by an inner oxide film, although in this case it was only $\sim 100 \mathrm{~nm}$ thick. The oxide layer was attached directly to the nanocrystalline layer. Fig. $4 \mathrm{~d}$ is HRTEM image of the nanocrystalline layer.

In Area 5 of Case 1, the surface layers could not be observed in conventional bright field images, with Fig. 4e just showing the nanocrystalline layer. However, HRTEM image, Fig. 4f, indicated that a thin, $\sim 20 \mathrm{~nm}$, surface layer existed.

Fig. 5a compares normalised EEL spectra from the carbonaceous layer, oxide film and substrate of Area 1 of Case 1. In addition, a standard carbon K-edge for amorphous carbon is provided in Fig. 5b. The C K-edge was only observed in the outer carbonaceous layer and was not found in the adjacent oxide film or substrate (spectrum is not shown here). The carbon K-edge observed here is very similar in fine structure to the standard amorphous carbon spectrum. This is also consistent with the high resolution imaging of this region.

Fig. 5 also shows EEL spectra taken from the oxide film. The $\mathrm{O}$ K-edge and $\mathrm{Cr} \mathrm{L}_{3,2}$-edge are clearly present, but no trace of $\mathrm{Co} \mathrm{L}_{3,2^{-}}$ edge was observed, suggesting the oxide film is chromium oxide. Not surprisingly, strong peaks of $\mathrm{Cr}_{3,2}$ and $\mathrm{Co}_{3,2}$ are seen in the substrate, with fine structure in the $\mathrm{Cr} \mathrm{L}_{3,2}$-edge similar in the substrate and oxide.

Fig. 6 compares normalised EEL spectra from carbonaceous layer and oxide film of Area 2 of Case 1. In the oxide film, clear O Kand $\mathrm{Cr} \mathrm{L}_{3,2}$-edges can be seen with small $\mathrm{C} \mathrm{K}$-edge (which might be the contamination), confirming that the oxide film is chromium oxide. In the carbonaceous layer, a strong C K-edge was observed,

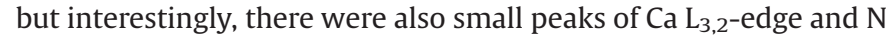
K-edge.

As Fig. 4e shows, no obvious surface layer can be seen in Area 5 of Case 1, therefore, random point analysis was performed on the near surface zone close to the substrate. Fig. 7 compares 


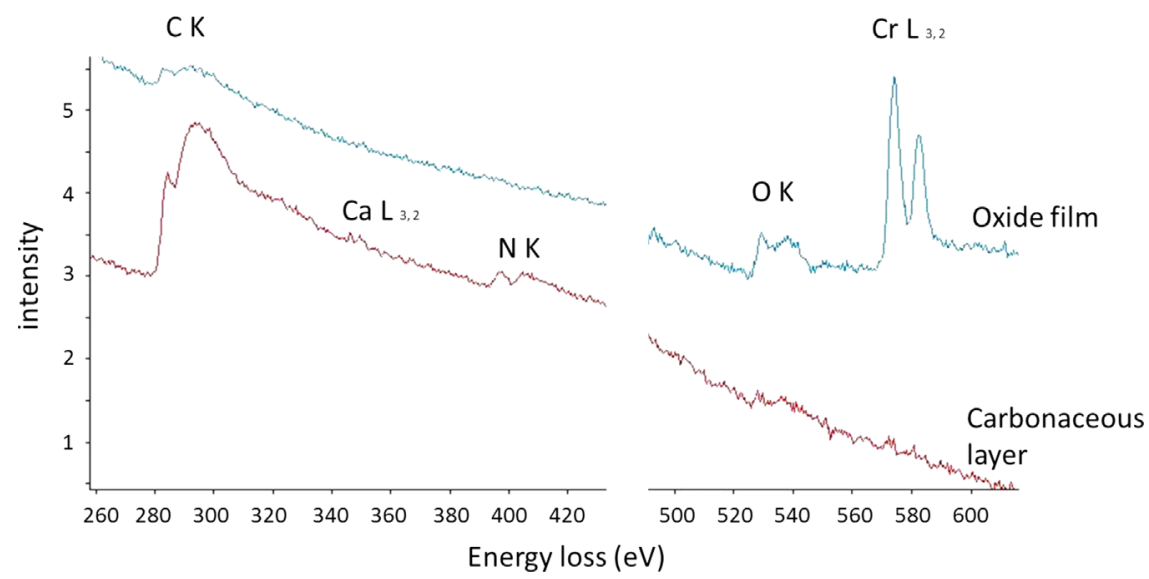

Fig. 6. Normalised experimental EEL spectra from oxide film and carbonaceous layer of Area 2 of Case 1.

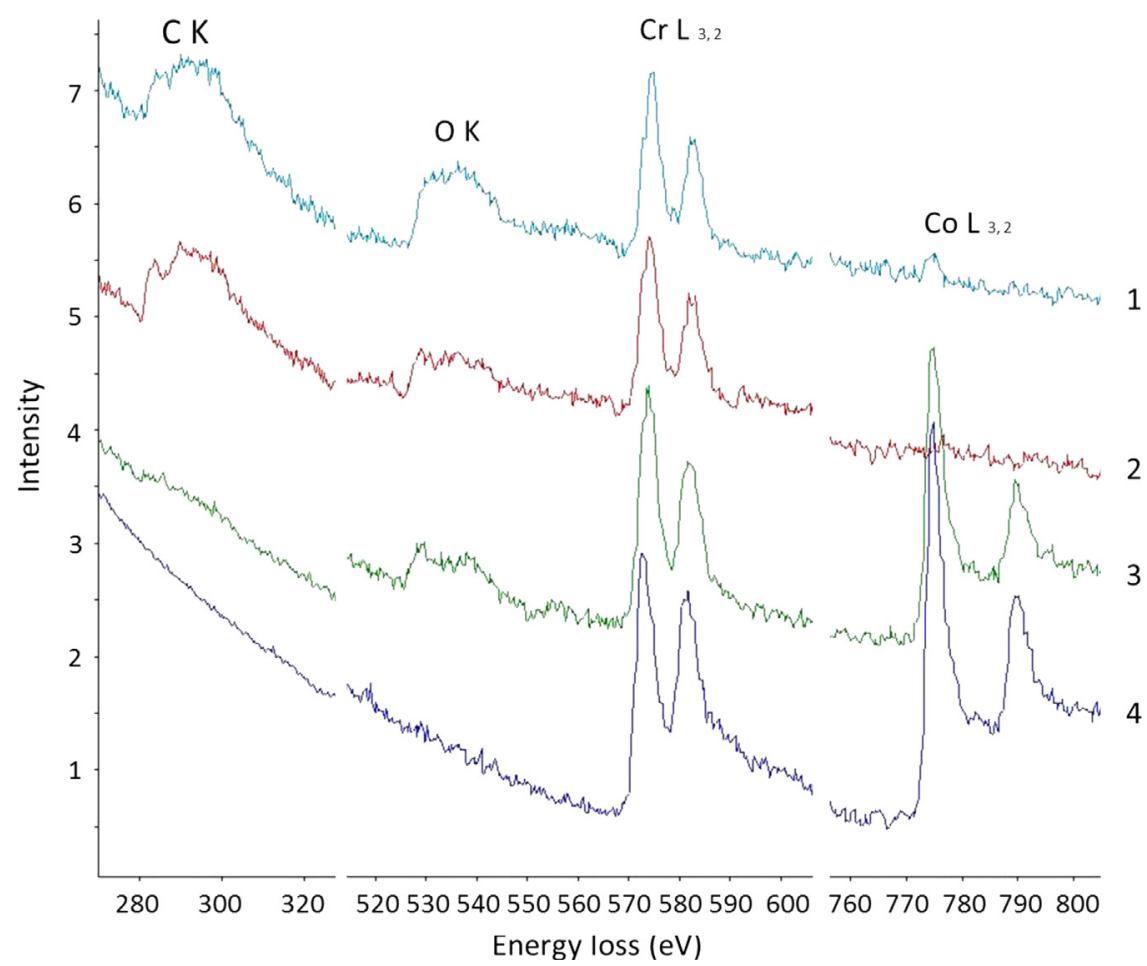

Fig. 7. Normalised experimental EEL spectra of four points, as indicated as 1, 2, 3 and 4, in near surface contact zone in Area 5 of Case 1.

normalised EEL spectra from four points in the near surface zone close the substrate, as indicated in Fig. 4e. Point 1 shows clear C K-edge, $\mathrm{O}$ K-edge and $\mathrm{Cr} \mathrm{L}_{3,2^{-}}$-edge, together with week Co $\mathrm{L}_{3,2^{-}}$ edge, suggesting there is a surface layer comprising a mixture of carbonaceous material and chromium oxide. Point 2 is similar to point 1. Points 3 appears to be just chromium oxide, with no carbon present. Point 4 only shows $\mathrm{Cr}_{\mathrm{L}} \mathrm{L}_{3}, 2$ and $\mathrm{Co}_{\mathrm{L}} \mathrm{L}_{3,2}$ peaks suggesting the spectrum came from the substrate.

\subsubsection{Case 2}

Bright field TEM images from FIB cross-sections of Areas 1, 2 and 5 of Case 2 are shown in Fig. 8. All the samples were taken in a longitudinal direction along the machining lines, as indicated in Fig. 2b, c and f. Fig. 8a and b are cross-sections of Area 1 of Case 1. A nanocrystalline layer of about $2 \mu \mathrm{m}$ thick, with a crystallite size was $\sim 50 \mathrm{~nm}$, was observed under the surface (Fig. 8a). In the near surface zone, two layers were observed between the metal surface and sputtered gold coating that acted as a label for the original outer surface (Fig. 8b). This is similar to the observation in Areas 1 of Case 1 . The thickness of the carbonaceous layer was about $80 \mathrm{~nm}$ with oxide film about $40 \mathrm{~nm}$. Again, the carbonaceous layer appeared uniform and amorphous, while the oxide layer appeared both amorphous and porous. However, in Area 2 of Case 2, only a thick layer, which is later confirmed to be carbonaceous layer by EELS (Fig. 10), was observed (Fig. 8c). HRTEM image (Fig. 8d) reveals a very thin layer, less than $10 \mathrm{~nm}$, between the carbonaceous layer and the substrate. This layer was later confirmed to be oxide film by EELS (Fig. 10). Fig. 8e shows an area between the metal surface and the gold label for Area 5 of Case 2. The region of bright contrast in this image is shown at high resolution in Fig. 8f, revealing an amorphous structure to this material.

Fig. 9 compares normalised experimental EEL spectra from the carbonaceous layers and oxide films from Area 1 of Case 1. It is interesting to note that in the carbonaceous layer, the majority of the $C$ K-edges have a $\pi *$ pre-peak (see Fig. 9 for such an example of from the carbonaceous layer 2), however, some of C K-edges do not exhibit the $\pi *$ pre peak (for example, the carbonaceous layer 

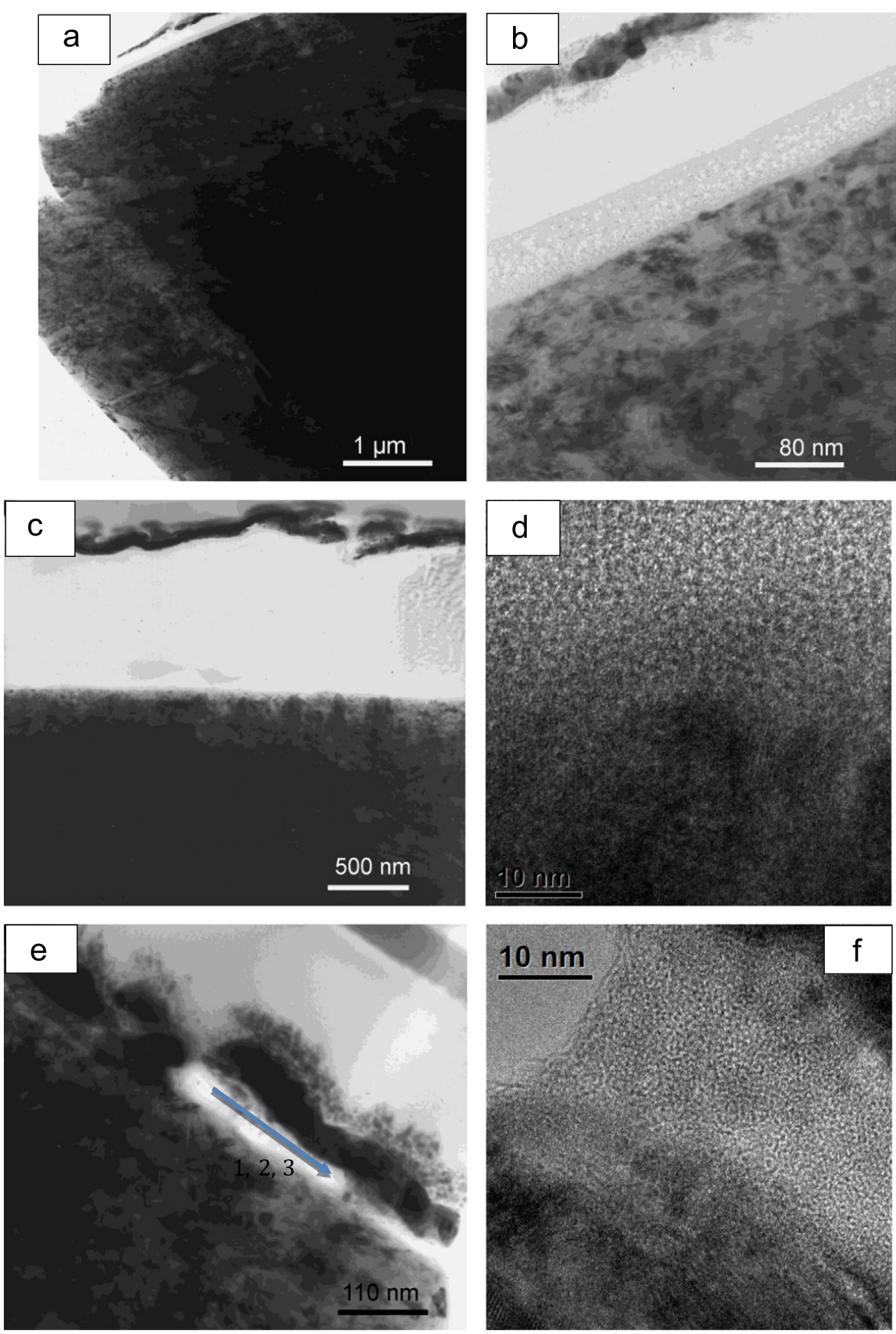

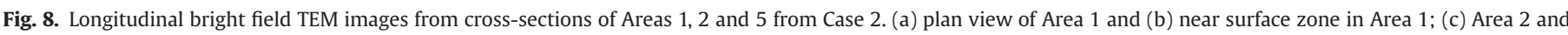

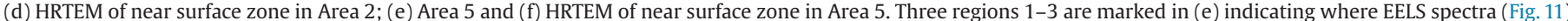
were taken.

1 in Fig. 9). Also in the oxide film, some only have $\mathrm{O}$ K-edge and $\mathrm{Cr}$ $\mathrm{L}_{3,2}$-edges, indicating chromium oxide, and some has an extra $\mathrm{C}$ K-edge, which might be caused by contamination.

Fig. 10 compares normalise EEL spectra from carbonaceous layer and oxide film from Area 2 of Case 2. It is worth noting that in the carbonaceous layer, a weak $\mathrm{N}$ K-edge is seen as well as a strong $\mathrm{C}$ K-edge. In the oxide film, $\mathrm{O} \mathrm{K}$ - and $\mathrm{Cr} \mathrm{L}_{3,2}$-edges are

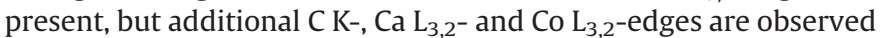
(Fig. 10), suggesting tribochemical reaction between surface layers (carbonaceous layer and oxide film) and the body fluid.

Fig. 11 compares normalised EEL spectra from three points in the region of bright contrast in Fig. 8e, taken from Area 5 of Case 2. A strong $\mathrm{C} \mathrm{K}$-edge and weak $\mathrm{O} \mathrm{K}$ - and $\mathrm{Cr}_{3,2}$-edges were observed all three points, suggesting a mixture of carbonaceous and oxide material with carbonaceous material the most dominant.

\section{Discussion}

\subsection{Surface morphologies of the taper interfaces}

Goldberg and Gilbert [29] analysed 231 modular hip implants to investigate corrosion and fretting of modular taper surfaces. The study presented a scoring range from 1 to 4 (mild to severe) to describe the severity of corrosion and fretting on the taper 


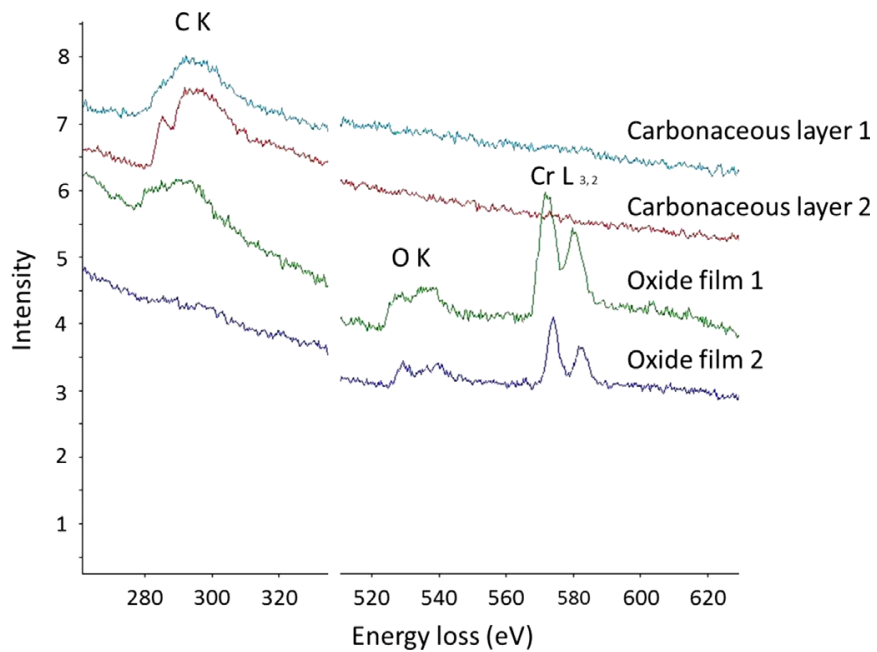

Fig. 9. Normalised experimental EEL spectra from carbonaceous layers and oxide films of Area 1 of Case 2.

interfaces. According to this scale, Case 1 and Case 2 would have scored a 4.

Five different areas were classified in this study: 1) Area 1, the distal end of the taper showing original machining marks; 2) Area 2 , showing similar machining marks compared with Area 1 which is also where the taper and the trunnion started overlapping, 3) Area 3, showing denatured protein piling up on the surface: 4) Area 4, dominated by heavy deformed materials; 5) Area 5, at the proximal end of the taper showing a highly polished region. Areas $1,2,3$ and 5 of Case 1 and Case 2 show similar surface morphologies, however, different morphologies are seen in Area 4 of Case 1 and Case 2, which might be due to machine cutting damage to Case 1.

\subsection{Subsurface changes of the taper interfaces}

The visualisation of subsurface deformation is important if an understanding of balance between corrosion and wear process of retrieved taper surfaces are to be differentiated. Fig. 12 shows a schematic diagram of the subsurface changes on the taper interfaces. In the near surface zone, three layers were present, namely (from top to bottom): a carbonaceous layer, an oxide film and a nanocrystalline layer in the surface of the metal. The thickness of various layers is different from area to area, as summarised in Table 1. In Area 5, a tribo-layer of carbonaceous material mixed with chromium oxide was present, in contrast to the separate carbonaceous layer and oxide films seen elsewhere. The thickness of this layer was of the order of $20 \mathrm{~nm}$ and could only be observed in high resolution TEM, and not visible in conventional TEM (Fig. 4e and $\mathrm{f}$ and Fig. 8e and f). EELS results show $\mathrm{C} \mathrm{K}-, \mathrm{O} \mathrm{K}-$ and $\mathrm{Cr} \mathrm{L}_{3,2}$-edges in the tribo-layer, indicating this layer is carbonaceous material mixed with metal and oxide particles, a result in agreement with Wimmer et al. [30]. The results are also in agreement with Bryant et al. [28] who studied retrieved cemented MoM prostheses and demonstrated that films on the worn surface were a complex mixture of chromium oxide, protein and amorphous carbon.

The existence of a carbonaceous layer in Area 1 (where the taper and trunnion were not overlapping) of both Case 1 and Case 2 suggests that the layer is not the product of tribochemical reaction, but as a result of normal protein adsorption to the surface. EELS results indicated only a C K-edge in the carbonaceous layer in Area 1 of both Cases 1 and 2. The majority of the C K-edges had a strong $\pi *$ pre-peak, which in the agreement with Liao et al. $[27,31]$. However, there were exceptions to this, such as the carbonaceous layer 1 in Area 1 of Case 2 (Fig. 9) which does not show the $\pi *$ pre-peak. It is difficult to say that this $\pi *$ pre-peak is a product of the wear process, however, it is commonly seen in amorphous carbon surface layers resulting from frictional surface contact [32], and is not present in carbon resulting from contamination, e.g. during sample preparation.

Interestingly, there was a significant increase in the thickness of the carbonaceous layer in Area 2 compared with Areas 1 and 5, for both Cases 1 and 2. Also, Ca $\mathrm{L}_{3,2}$-edges and $\mathrm{N}$ K-edge were observed in the carbonaceous layer in Area 2 of Case 1 and Case 2 in EELS (Figs. 6 and 9), suggesting tribochemical reactions between the carbonaceous layer and body fluid when the taper and trunnion were overlapping. Wimmer et al. believed that in vivo, tribochemical reactions between metal and surrounding synovial fluid result in the generation of this metallo-organic carbonaceous layer [30]. In addition, Wimmer et al. [30] also demonstrated that a tribofilm with embedded carbonaceous material can be generated by mechanically polishing the surfaces with bovine calf serum (BCS) as a lubricant. In our case, the carbonaceous layer only contained $\mathrm{C}$, $\mathrm{Ca}$ or $\mathrm{N}$, with no metal or metal oxide particles and therefore it was not formed through a mechanically mixing mechanism. The observation that the carbonaceous layer was thicker in Area 2 compared to Area 1 and that the layer contained $\mathrm{Ca}$ and $\mathrm{N}$ in Area 2 but not in Area 1 suggests that, although the formation mechanism was probably the same, there was local differences in $\mathrm{pH}$ and oxygen content leading to differences in the formation of this layer.

In Areas 1 and 2 of Cases 1 and 2, a porous oxide film was observed, as indicated in Fig. 4a and c and Fig. 8a and c. EELS results (Figs. 5, 6, 9, and 10) show only $\mathrm{O}$ K-edge and $\mathrm{Cr} \mathrm{L}_{3,2}$-edges, suggesting that it is only chromium oxide. However, the oxide is amorphous with unknown stoichiometry, and does not correspond to $\mathrm{Cr}_{2} \mathrm{O}_{3}$, which has been assumed to be present by other researchers $[28,30]$. The thickness of this oxide film varies over small distances, being as thick as $100 \mathrm{~nm}$ in some Areas 1 and 2 of Case 1 (Fig. 4), but equally around half that value at $\sim 50 \mathrm{~nm}$, in Area 1 of Case 2 (Fig. 8) and as small as $10 \mathrm{~nm}$ in Area 2 of Case 2 (Fig. 8). Orthopaedic metals are artificially over-passivated [31] to build up a protective oxide film before implantation, which explains the thick oxide film observed in Area 1 of both Case 1 and Case 2. However, during service, the passive oxide film can be damaged by fretting wear, like in Area 2 of Case 2; or new passive film can be formed and serve as a barrier to further corrosion, such as Area 2 of Case 1. The extent of reformation depends on the local $\mathrm{pH}$ and the extent of oxygen depletion, which are not known. The passivation and repassivation of the oxide film explain the various thickness of the oxide film.

A layer of nanocrystalline material with a grain size of $10 \mathrm{~nm}$ have been widely observed in CoCrMo bearing surfaces by various authors [33-36] and has even been observed on the surface of an alumina femoral head [37]. Buscher et al. [34] examined the crosssection surface of retrieved low-carbon CoCrMo hip replacement, as well as pin-on-disc test. Fine granular crystals of $\sim 50 \mathrm{~nm}$ in size were present in the outer $\sim 1 \mu \mathrm{m}$ of the surface. Pourzal et al. [35] studied a retrieved hip resurfacing and reported a nanocrystalline layer with a thickness of $250-400 \mathrm{~nm}$ and grain size of $25-40 \mathrm{~nm}$. Rainforth et al. [36] examined both in-vivo and in-vitro MoM prostheses and found grain sizes of $35 \pm 8 \mathrm{~nm}$ with some equiaxed grains but mainly elongated grains, but with no evidence of any preferred crystallographic orientation.

In the current work, the nanocrystalline layer at the surface of the taper will have been formed during the machining operation. The full role of this layer is not entirely clear [36], but it is believed to have a significant effect on the tribological and tribocorrosion performance of the surface. The depth of this layer in a nonoverlap part of the taper extended to around $5 \mu \mathrm{m}$ below the 


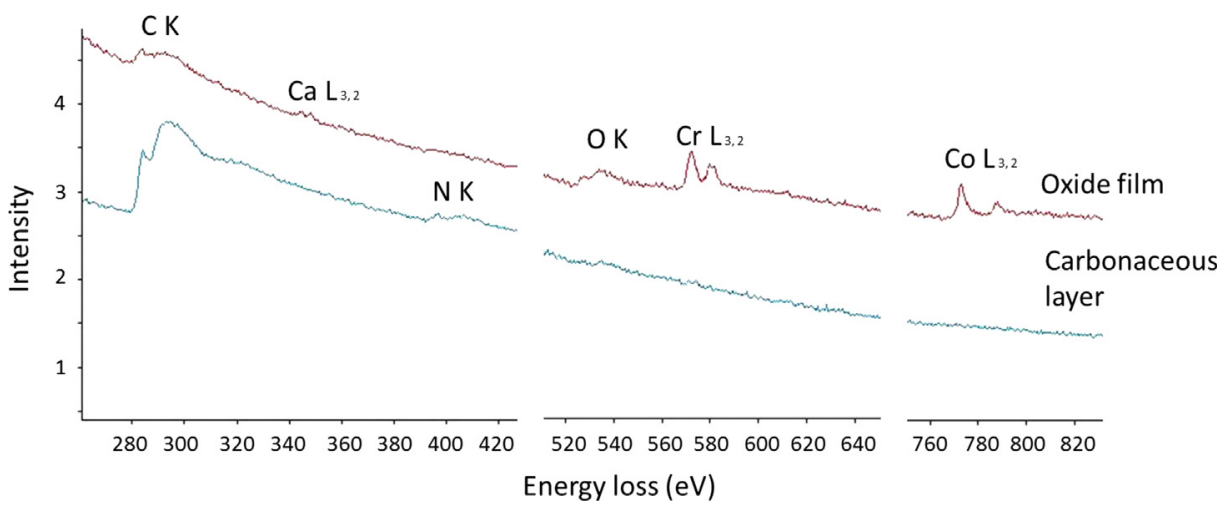

Fig. 10. Normalised experimental EEL spectra from carbonaceous layer and oxide film of Area 2 of Case 2.

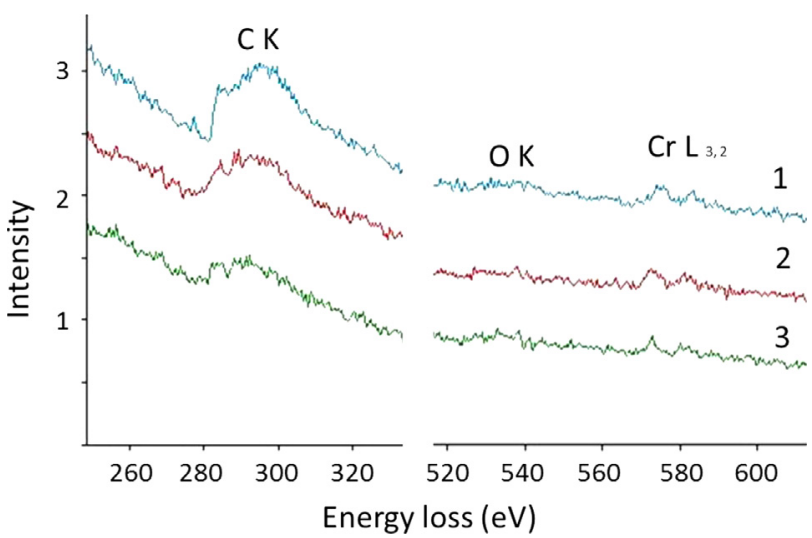

Fig. 11. Normalised experimental EEL spectra of three points, as indicated as 1 , 2 and 3 in Fig. 8e, in near surface contact zone in Area 5 of Case 1.

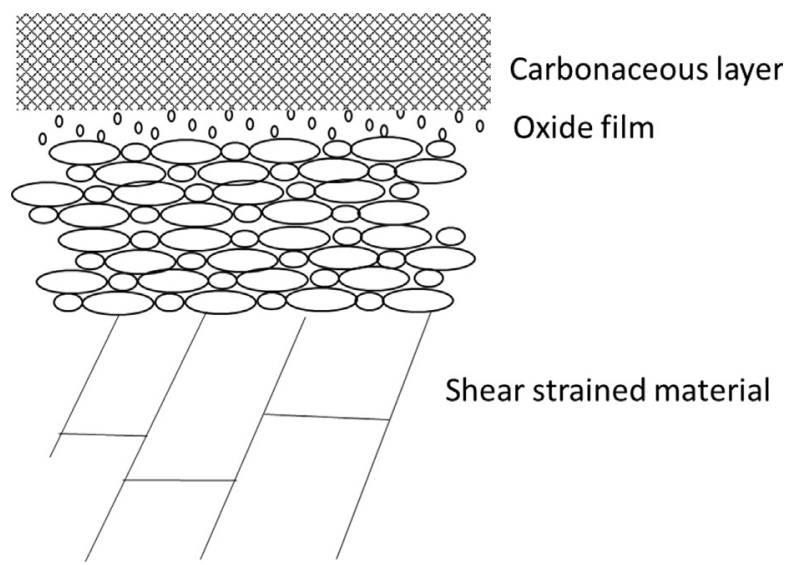

Fig. 12. Schematic diagram of subsurface microstructure of the taper interface.

Table 1

Summarised thickness of carbonaceous layer, oxide film and nanocrystalline layer in Areas 1, 2 and 5 of Case 1 and Case 2.

\begin{tabular}{llll}
\hline & Area 1 & Area 2 & Area 5 \\
\hline Carbonaceous layer & $\sim 80-100 \mathrm{~nm}$ & $\sim 200-500 \mathrm{~nm}$ & $\sim 20 \mathrm{~nm}$ \\
Oxide film & $\sim 50-100 \mathrm{~nm}$ & $\sim 10-50 \mathrm{~nm}$ & \\
Nanocrystalline layer & $\sim 5 \mu \mathrm{m}$ & $\sim 1 \mu \mathrm{m}$ & $\sim 2 \mu \mathrm{m}$ \\
\hline
\end{tabular}

surface. However, in other regions that had been overlapped, the depth was greatly reduced (1-4 $\mu \mathrm{m})$. This strongly suggests that a significant amount of the surface layer had been removed by corrosion and wear, which will contribute to the metal ion and wear debris release. Moreover, the resultant structure that was left was different, with a different surface activity (see the microstructural gradation in Fig. 3).

\section{Conclusions}

(a) The taper interface varies along the length of the tapers. The original machining marks from the manufacture process were observed at the distal end of the taper. Distal to this region, evidence of mechanical damage was seen where the taper and trunnion were overlapping.

(b) Site-specific FIB/TEM cross-sections from those regions all show evidence of the oxide film, with thickest film on the original machining marks region at the distal end of the taper $(\sim 50 \mathrm{~nm})$ and thinnest film on the highly polished region at the proximal end of the taper (few $\mathrm{nm}$, mixed with carbonaceous material).

(c) An amorphous carbonaceous layer was observed in all regions as the outermost layer. The thickest carbonaceous film was seen in the region close to the distal end of the taper where the taper and the trunnion started overlapping. Evidence of tribochemical reaction between carbonaceous layer and protein was observed. EEL spectra from this film often exhibit a $\pi *$ peak, which is constituent with TEM observations of carbonaceous films following tribological contact.

(d) An oxide film was observed below the carbonaceous film, on the surface of the metal. High resolution TEM results showed the oxide film had an amorphous and porous structure. EELS confirmed the film was chromium oxide, but the oxide was not crystalline $\mathrm{Cr}_{2} \mathrm{O}_{3}$ as often assumed in the literature. The thickness of the oxide layer varied considerably over small distances, reflecting changes resulting from the fretting contact.

(e) A nanocrystalline layer was observed at the outer surface of the metal in all areas examined. This was derived from the machining process during manufacture. The thickness of this layer was $5 \mu \mathrm{m}$ in regions where contact had been minimal, but reduced to $1-4 \mu \mathrm{m}$ in regions where there had been contacted. This indicated that material had been removed either by corrosion or wear, contributing to the metal ion and wear debris release.

\section{References}

[1] Smith A, Dieppe P, Vernon K, Porter M, Blom AW. Failure rates of stemmed metal-on-metal hip replacements: analysis of data from the National Joint Registry of England and Wales. Lancet 2012;380(9855):1759-66. 
[2] De Steiger RN, Hang JR, Miller LN, Graves SE, Davidson DC. Five-year results of the ASRXLA Acetabular System and the ASR Hip Resurfacing System: an analysis from the Australian Orthopaedic Association National Joint Replacement Registry. J Bone Joint Surg Am 2011;93:2287-93.

[3] Garbuz DS, Tanzer M, Greidanus NV, Masri BA, Duncan CP. The John Charnley Award: metal-on-metal hip resurfacing versus large-diameter head metal-onmetal total hip arthroplasty: a randomized clinical trial. Clin Orthop Relat Res 2010;468:318-25.

[4] Beaule PE, Kim PR, Hamdi A, Fazekas A. A prospective metal ion study of largehead metal-on-metal bearing: a matched-pair analysis of hip resurfacing versus total hip replacement. Orthop Clin North Am 2011;42:251-7.

[5] Langton DJ, Sidaginamale R, Lord JK, Nargol AV, Joyce TJ. Taper junction failure in large-diameter metal-on-metal bearings. Bone Joint Res 2012:1:56-63.

[6] Matthies AK, Racasan R, Bills P, Panagiotidou A, Blunt L, Skinner J, et al Materials loss at the taper junction of large head metal on metal hip replacements. J Orthop Res 2013;31(11):1677-85.

[7] Fricka KB, Ho H, Peace WJ, Engh Jr CA. Metal-on-metal local tissue reaction is associated with corrosion of the head taper junction. J Arthroplast 2012;27(8 Suppl):S26-31.

[8] Chana R, Esposito C, Campbell PA, Walter WK, Walter WL. Mixing and matching causing taper wear: corrosion associated with pseudo-tumour formation. J Bone Joint Surg Br 2012;94B(2):281-6.

[9] Meyer H, Mueller T, Goldau G, Chamaon K, Ruetschi M, Lohmann C. Corrosion at the cone/taper interface leads to failure of large-diameter metal-on-metal total hip arthroplasties. Clin Orthop Relat Res 2012;470(11):3101-8.

[10] Gill IPS, Webb J, Sloan K, Beaver RJ. Corrosion at the neck-stem junction as a cause of metal ion release and pseudotumour formation. J Bone Joint Surg Br 2012;94B(7):895-900

[11] Lindgren JU, Brismar BH, Wikstrom AC. Adverse reaction to metal release from a modular metal-on-polyethylene hip prosthesis. J Bone Joint Surg $\mathrm{Br}$ 2011;93B(10):1427-30.

[12] Mao X, Tay GH, Godbolt DB, Crawford RW. Pseudo-tumor in a well-fixed metal-on-polyethylene uncemented hip arthroplasty. J Arthroplast 2012;27 (3):493.

[13] Cook RB, Benjamin JRF, MBBS Bolland, Wharton JA, Tilley S, Latham JM, Wood RJK. Pseudo-tumour formation due to tribocorrosion at the taper interface of large diameter metal on polymer modular total hip replacements. J Arthroplast 2013;28:1430-6.

[14] Langton D, Sidaginamale R, Lord J, Joyce T, Natu S, Nargol A. Metal debris release from taper junctions appears to have a greater clinical impact than debris released from metal on metal bearing surfaces. Bone Joint J 2013;95B (S1):S28.

[15] Hart AJ, Matthies AK, Racasan R, Bills P, Panagiotidou A, Blunt L, et al. Taper wear contributes only a third of the total volumetric material loss in large head metal on metal hip replacement. In: Proceedings of the British orthopaedic research society annual meeting, 2012, London UK. (〈http://eprints. hud.ac.uk/15022/>).

[16] Cooper HJ, Della Valle CJ, Berger RA, Tetreault M, Paprosky WG, Sporer SM, et al. Corrosion at the head-neck taper as a cause for adverse local tissue reactions after total hip arthroplasty. J Bone Joint Surg Am 2012;94 (18):1655-61.

[17] Kurtz SM, Kocagoz SB, Hanzlik JA, Underwood RJ, Gilbert JL, MacDonald DW, et al. Do ceramic femoral heads reduce taper fretting corrosion in hip arthroplasty? A retrieval study Clin Orthop Relat Res 2013;471:3270-82.

[18] Gilbert JL, Buckley CA, Jacobs JJ. In-vivo corrosion of modular hip prosthesis components in mixed and similar metal combinations: the effect of crevice, stress, motion and alloy coupling. J Biomed Mater Res 1993;27:1533-44.
[19] Jacobs JJ, Gilbert JL, Urban RM. Current concepts review-corrosion of metal orthopaedic implants. J Bone J Sur 1998;80A(2):268-82.

[20] Gilbert JL. Mechanically Assisted Corrosion of Metallic Biomaterials. ASM international Handbook-13 (C)-Corrosion. 2006. p. 826-36.

[21] Hodgson AWE, Kurz S, Virtanen S, Fervel V, Olsson COA, Mischler S. Electrochim Acta 2004;49:2167-78.

[22] Yan Y, Neville A, Dowson D. Biotribocorrosion and appraisal of the time dependence of wear and corrosion interactions Part I: the role of corrosion. J Phys D: Appl Phys 2006;39:3206-12.

[23] Neville A, Yan Y, Dowson D. Tribo-corrosion properties of cobalt-based medical implant alloys in simulated biological environments. Wear 2007;263:1105-11.

[24] Virtanen S, Milosev I, Gomez-Barrena E, Trebse R, Salo J, Konttinen YT. Acta Biomater 2008;4:468-76.

[25] Wimmer MA, Sprecher C, Hauert R, Tager G, Fischer A. Tribochemical reaction on metal-on-metal hip joint bearings a comparison between in-vitro and invivo results. Wear 2003;255:1007-14.

[26] Wimmer MA, Fischer A, Buscher R, Pourzal R, Sprecher C, Hauert R, et al. Wear mechanisms in metal-on-metal bearings: the importance of tribochemical reaction layers. J Orthop Res 2010;28:436-43.

[27] Liao Y, Pourzal R, Wimmer MA, Jacobs JJ, Fischer A, Marks LD. Graphitic tribological layers in metal-on-metal hip replacements. Science 2011:334:1687-90.

[28] Bryant M, Ward M, Farrar R, Freeman R, Brummitt K, Nolan J, et al. Failure analysis of cemented metal-on-metal total hip replacements from a single centre cohort. Wear 2013;301:226-33.

[29] Goldberg JR, Gilbert JL, Jacobs JJ, Bauer TW, Paprosky W, Leurgans S. A multicentre retrieval study of the taper interfaces of modular hip prostheses. Clin Orthop Relat Res 2002;401:149-61.

[30] Wimmer MA, Mathew MT, Laurent MP, Nagelli C, Liao Y, Marks LD, et al. Tribochemical reaction in metal-on-metal hip joints influence wear and corrosion. In: Steven MK, Greenwald AS, William MM, Lemons JE, editors. Metal-on-Metal Total Hip Replacement Devices. New York: ASTM International; 2013. p. 292-309.

[31] Liao Y, Hoffman E, Wimmer M, Fischer A, Jacobs J, Marks L. CoCrMo metal-onmetal hip replacements. Phys Chem Chem Phys 2013;15:746-56.

[32] Zhou Z, Ross IM, Ma L, Rainforth WM, Ehiasarian AP, Hovsepian P. Wear of hydrogen free $\mathrm{C} / \mathrm{Cr}$ PVD coating against $\mathrm{Al}_{2} \mathrm{O}_{3}$ at room temperature. Wear $2011 ; 271: 2150-6$

[33] Fischer A. Subsurface microstructural alterations during sliding wear of biomedical metals. Modeling and experimental results. Comput Mater Sci 2009;46:585-90.

[34] Bucher R, Fischer A. The pathways of dynamic recrystallization in all-metal hip joints. Wear 2005;259:887-97.

[35] Pourzal R, Theissmann R, Morlock M, Fischer A. Micro-structural alterations within different areas of articulating surfaces of a metal-on-metal hip resurfacing system. Wear 2009;267:689-94.

[36] Rainforth WM, Zeng P, Ma L, Nogiwa-Valdez A, Stewart T. Dynamic surface microstructural changes during tribological contact that determine the wear behavior on hip prostheses: metals and ceramics. Faraday Discuss 2012;156:41-57.

[37] Zeng P, Rainforth WM, Inkson BJ, Stewart TD. Transmission electron microscopy analysis of worn alumina hip replacement prostheses. Acta Mater 2012;60:2061-72. 